\title{
PENINGKATAN KOMPETENSI MAHASISWA UIN SUNAN GUNUNG DJATI BANDUNG DALAM MERANCANG RENCANA PELAKSANAAN PEMBELAJARAN (RPP) MATEMATIKA BERBASIS NILAI-NILAI ISLAM
}

\author{
Asep Jihad1 \\ ${ }^{1}$ Prodi Pendidikan Matematika, UIN Sunan Gunung Djati Bandung, JL.AH Nasution No. \\ 105 Cibiru Bandung
}

E-mail: asjiehad@uinsgd.ac.id

\begin{abstract}
ABSTRAK
Mahasiswa prodi pendidikan matematika selain memiliki kemampuan menguasai konsep matematika, mengajar juga harus mampu membuat Lesson Plan (LP) berdasarkan nilai Islam sebagai ciri khas mahasiswa UIN SunanGunungDjati Bandung. Kemampuan siswa untuk mengembangkan LP, masih belum optimal, peneliti tertarik untuk membuat model pembelajaran dalam meningkatkan kemampuan mempersiapkan LP. Penelitian ini menggunakan metode deskriptif evaluatif. Penelitian ini dilakukan pada 40 siswa jurusan matematika UIN SunanGunungDjati Bandung. Penelitian ini bertujuan untuk menganalisis kemampuan siswa dalam mempersiapkan Matematika LP berdasarkan nilai-nilai Islam, instrumen yang digunakan dalam kuesioner dan tes kemampuan untuk membangun LP berbasis nilai-nilai Islam. Hasil penelitian, pelaksanaan ceramah tentang peningkatan kemampuan siswa untuk merancang LP berdasarkan nilai Islam termasuk kategori sedang, hasil LP berbasis nilai Islam masih belum muncul dalam konten matematika, tujuan pembelajaran dan evaluasi. Dengan demikian, desain model kuliah di departemen matematika harus berkolaborasi
\end{abstract}

Kata kunci: Kompetensi, RPP, Berbasis Nilai Islam

\begin{abstract}
Students of department of mathematics education besides having the ability to master math concept, teaching also must be able to make Lesson Plan (LP) based on Islamic value as characteristic of UIN SunanGunungDjati Bandung student. The ability of students to develop LP, still not optimal, the researcher is interested to make the model of learning in improving the ability of preparing LP. The research used descriptive evaluative method. The research was conducted on 40 students of mathematics department UIN SunanGunungDjati Bandung. This study aims to analyse the ability of students in preparing the LP Mathematics based on Islamic values, the instruments used in the questionnaire and the test of the ability to construct Islamic values-based LP. The results of the research, the implementation of lectures on improving the student's ability to design the LP based on Islamic value including the medium category, the results of Islamic values-based LP still have not appeared in mathematical content, learning objectives and evaluation. Thus, the design of lecturing models in the mathematics department should collaborate between with mathematical content, pedagogy and religion
\end{abstract}

Keywords: Competence, RPP, Based on Islamic Values 


\section{PENDAHULUAN}

Visi UIN Sunan Gunung Djati "Wahyu Memandu Ilmu" pada dasarnya bertujuan untuk menjadikan Wahyu ( ayat-ayat Quran) sebagai pemandu bagi pengembangan keilmuan dan kependidikan di seluruh Fakultas yang ada dilingkungan UIN Sunan Gunung Djati Bandung termasuk lulusan Fakultas Tarbiyah dan Keguruan untuk semua jurusan yang ada. Wahyu memandu ilmu harus terjadi pada aspek pendidikan (pembelajaran), penelitian, pengabdian, pembimbingan, maupun administratif. gerakan wahyu memandu ilmu juga harus berproses secara lebih sistematis dan lebih nyata. dalam berbagai aspek kehidupan akademik (Nanat, 2008).

Tafsir (2007:72) mengatakan bahwa dalam rangka mengimplementasikan visi dan program wahyu memandu ilmu perlu dirumuskan secara jelas bagaimana nila Islam dalam program dan praktik pembelajaran di semua program studi di lingkungan Fakultas Tarbiyah dan Keguruan termasuk di prodi pendidikan Matematika.

Penerapan nilai-nilai Islam dalam proses pembelajaran diharapkan dapat menimbulkan kesadaran para peserta didik. Pembelajaran sains yang menyadarkan terhadap nilai kebaikan dan keselamatan akan menciptakan kebaikan antar-sesama manusia (sains berbasis humaniora) (Sarkim, 1998: 45). Pembelajaran yang mengandung kebaikan maupun keselamatan dalam kaitan berhubungan dengan Yang Maha kuasa dalam wujud berakhlak mulia (Saiful, 2000: 103). Sejalan dengan itu diketahui bahwa pembelajaran mata pelajaran matematika sebagai: alat, pola pikir, dan ilmu atau pengetahuan. Ketiga fungsi matematika tersebut hendaknya dijadikan acuan dalam pembelajaran matematika sekolah.

Beberapa penelitian mengungkapkan bahwa program pembelajaran sains berbasis IMTAQ akan mendorong adanya pemahaman terhadap integrasi nilai agama Islam dan sains. Integrasi nilai agama Islam dan nilai terpadu melalui pembelajaran sains. Nilai agama Islam (spiritual) mendorong agar sesuatu proses pembelajaran menjadi penting (berguna), baik (benar) yang bersumber dari Al-Quran. Nilai yang memotivasi tumbuhnya keyakinan dan ketaatan beribadah kepada-Nya.

Hasil penelitian lain, dikemukakan (Obaidat dan Malkawi,) dalam Subroto (2009:1) kemampuan mahasiswa terhadap pembelajaran dan rendahnya keterampilan mahasiswa menggunakan matematika dalam fisika terjadi karena penggunaan instrumen penilaian dalam pembelajaran yang kurang tepat, sehingga muncul sikap negatif, mahasiswa mengeluh dan merasa cemas untuk belajar (Sugilar,2017) karena itu Arends (2004) berpendapat strategi perkuliahan sangat berpengaruh terhadap minat, motivasi, bahkan persepsi mahasiswa terhadap mata kuliah tersebut.

Salah satu program studi non-Pendidikan Agama Islam yang di selengarakan di Fakultas Tarbiyah dan Keguruan adalah prodi Pendidikan Matematika. Konsekuensi wahyu memandu ilmu untuk lulusan Prodi Pendidikan Matematika memiliki kompetensi yang memadai tentang perpaduan antara nilai matematika dengan nilai Islam, salah satu kompetensinya kemampuan mahasiswa merancang Lesson Plan (LP) matematika berbasis Islam, permasalahan pokok yang timbul adalah bagaimana mengembangkan program pembelajaran yang mendukung wahyu memandu ilmu sehingga lulusanya memiliki kompetensi tersebut.

Menurut Gagne (1975) dalam mempelajari matematika setiap warga belajar harus belajar bagaimana mengubah simbol-simbol ke dalam susunan kata-kata yang dapat dimengerti, mengubah pecahan menjadi desimal dalam matematika, menerapkan kata dalam kalimat, bagaimana mengubah kalimat menjadi kalimat pertanyaan, sementra itu Karso (2014) menjelaskan pembelajaran matematika, perlu 
Peningkatan Kompetensi Mahasiswa UIN Sunan Gunung Djati Bandung dalam Merancang RPP Matematika

Berbasis Nilai-Nilai Islam

memahami teori-teori belajar yang dijadikan pedoman dalam membuat suatu metode pembelajaran. Salah satu teori tersebut adalah Teori William Brownell yang menyatakan bahwa: "Belajar matematika merupakan belajar bermakna, dalam arti setiap konsep yang dipelajari harus benar-benar dimengerti sebelum sampai pada latihan atau hafalan."(Karso, 2014). Pembelajaran matematika bermakna, memungkinkan adanya penanaman nilai yang menjadi bagian yang terintegrasi dari proses pembelajaran.

Perkuliahan matematika umumnya dilakukan secara parsial, tidak mengintegrasikan nilainilai agama dalam muatan-muatan pelajarannya. Fokus pembelajaran parsial hanya pada ketercapaian tujuan materi pelajaran yang cenderung hanya menyentuh aspek kognitif. Akibatnya, pelajaran matematika kering dari pesan-pesan moral dan upaya pembentukan pribadi yang utuh, padahal Crow and Crow (1963), Gagne (1965), dan Hilgard and Bower (1966) dalam Knowles (1990), mengemukakan inti proses belajar adalah perubahan pada diri individu dalam aspek-aspek pengetahuan, sikap, keterampilan, dan kebiasaan sebagai produk dan interaksinya dengan lingkungannya.

Untuk menanamkan nilai-nilai Islam melalui proses perkuliahan matematika, diperlukan strategi yang tepat. Beberapa strategi pembelajaran yang dikaitkan dengan penanaman nilai-nilai ajaran islam yang dapat dilakukan dalam pembelajaran mata pelajaran matematika, adalah selalu menyebut nama Allah, penggunaan istilah, Ilustrasi visual, aplikasi atau contoh-contoh, menyisipkan ayat atau hadits yang relevan, penelusuran sejarah, jaringan topik, simbol ayat-ayat kauniah. Dalam implementasinya, sebelum pembelajaran dimulai, ditradisikan diawali dengan membaca Basmalllah dan berdoa bersama-sama dan setelah selesai perkuliahan bersama-sama dengan mengucap Alhamdulillah. Dosen dituntut untuk mengingatkan kepada peserta didik betapa pentingnya kita selalu ingat, mengatas namakan Allah untuk segala aktivitas dan bersyukur kepada Allah, apa lagi ketika sedang menggali ilmu-Nya Allah.

Implementasi secara makro dapat dilakukan dengan mengintyegrasikan materi perkuliahan matematika dengan nilai-nilai Islam secara untuh, kesatuan koherensi antara pembelajaran matematika dan agama teraplikasi dalam bentuk: science matter integrated with religious matter (mengintegrasikan materi pelajaran umum dengan materi pelajaran pendidikan agama) yakni nilai-nilai Islami inklusif dalam penyampaian pembelajaran matematika atau sebaliknya religious matter integrated with science matter (mengintegrasikan materi pelajaran agama dengan mata pelajaran umum).

Secara operasional implementasinya sebagai berikut: a) mengembangkan Materi Perkuliahan Matematika bersumber Islam (Al Quran dan Hadits). Impelentasi matematika dengan mengembangkan ide-ide matematis dalam sumber Islam yang utama yaitu alQuran ada yang bersifat eksplisit dan implisit. Contoh materi matematika yang muncul secara ekplisit misalnya Bilangan, relasi bilangan, operasi bilangan, rasio dan proporsi, himpunan, dan pengukuran, sementara yang implicit muncul seperti Relasi, fungsi, estimasi, statistika, dan pemodelan matematika merupakan contoh materi-materi matematika yang disebutkan secara implisit dalam al-Quran. Abdussakir (2006a), Abdussakir (2007), Basya (2005) membahas tuntas bagaimana matematika dikembangkan dari al-Quran; b) Matematika sebagai landasan Melaksanakan Ajaran Islam.

Model integrasi dibangun dengan mebedah relevansi matematika dalam kontek agama, misalnya menggunakan matematika dalam konteks fikih, yaitu penentuan ukuran dua kulah, shalat, puasa, zakat, haji, dan pembagian harta waris (faraidl) Muniri (2016), mengembangkan potensi intelektual sekaligus potensi spiritual siswa (Djauhari, 2008). 
Penyebutan afala tatafakkarun (apakah tidak berpikir), afala ta'qilun/ya'qilun (apakah tidak bernalar), dan afala tadzakkarun (apakah tidak belajar) mendorong manusia untuk mengembangkan potensi intelektualnya; c) Menjelasakan Keajaiban Alquran dengan Matematika. Ada beberapa bilangan istimewa yang memiliki keajaiban misalkan 7 , angka 9 angka 11 dan angka 19. Ada beberapa filsuf islam mengungkap konsep bilangan 7 yaitu Rashad Khalifa (1974), Ahmad Deedat (1979), Fahmi Basya (2003), Abdurrazzaq Naufal (2005), Abu Zahra an-Najdi (2006), Abah Salma Alif Sampayya (2007), Caner Taslaman (2010), Abdussakir (2006a, 2006b, 2007) mengkaji keajaiban angka 19 dalam al-Quran. Abdud Daim al-Kahil (2008) mengkaji keajaiban bilangan 7 dalam al-Quran melalui konsep himpunan sedangkan Arifin Muftie (2007) mengkaji keajaiban bilangan 11 dalam al-Quran. Abdurrazzaq Naufal (2005) juga mengkaji keajaiban statistik dalam al-Quran. Soemabrata (2006a dan 2006b) mengkaji aspek-aspen numerik al-Quran; Mengajarkan Matematika dengan Nilai-nilai Islam. Kajian terkait internalisasi nilai Islami dalam pembelajaran matematika telah dilakukan. Abdussakir (2005, 2006, 2007, 2009) mulai mencoba mengenalkan konsep integrasi matematika dan Islam serta internalisasi nilainilai Islam melalui analogi dan interpretasi pada konsep-konsep matematika. Kohar (2010) membahas rumusan pembelajaran matematika yang mengintegrasikan nilai Islam. Kurniati (2015) mencoba menawarkan caracara pembelajaran matematika terintegrasi dengan Islam untuk menanamkan nilai-nilai Islam. La Jaama (2015) mencoba melalukan internalisasi nilai kebenaran niat dan cara serta keikhlasan melalui analogi.

Salah satu program studi non-Pendidikan Agama Islam yang di selengarakan di Fakultas Tarbiyah dan Keguruan adalah prodi Pendidikan Matematika. Konsekuensi wahyu memandu ilmu untuk lulusan Prodi Pendidikan Matematika memiliki kompetensi yang memadai tentang perpaduan antara nilai matematika dengan nilai Islam, salah satu kompetensinya kemampuan mahasiswa merancang perencanaan pembelajaran (RPP) matematika berbasis Islam, permasalahan pokok yang timbul adalah bagaimana mengembangkan program pembelajaran yang mendukung wahyu memandu ilmu sehingga lulusanya memiliki kompetensi tersebut. Berdasarkan uraian di atas, peneliti merumuskan beberapa masalah sebagai berikut: bagaimana model pembelajaran matematika yang mengintegrasikan nilai-nilai Islam bagi mahasiswa Prodi pendidikan matematika?; bagaimana kompetensi mahasiswa Prodi pendidikan matematika dalam mengintegrasikan nilai-nilai Islam pada materi matematika dalam merencanakan pelaksanaan pembelajaran matematika?

\section{METODE PENELITIAN}

Metode yang digunakan dalam penelitian ini adalah metode deskriptif analitik, dengan pendekatan fenomenologik, dengan langkahlangkah : 1) epoche, yaitu menangguhkan atau menahan diri dari segala keputusan positif. Menahan diri mengandung arti menagguhkan dalam pengambilan keputusan, penting artinya agar apa yang ditemukan dapat diungkap makna esensialnya; 2) ideantion, yakni menemukan esensi realitas yang menjadi sasaran pengamatan reduksi objek individulanya, item dari objek pengamatan itu.

Adapun objek penelitian dalam penelitian ini adalah dosen yang mengampu mata kuliah Bidang Matematika, terutama dosen Perencanaan Pembelajaran Matematika dan microteaching serta mahasiswa Prodi Matematika Fakultas Tarbiyah UIN Sunan Gunung Djati Bandung tahun ajaran 2017 yang mengambil mata kuliah micro teaching berjumlah 40 mahasiswa dan 10 orang dosen. Sementara untuk angket di sebar ke seluruh dosen mata kuliah matematika dan mahasiswa yang mengambil mata kuliah micro teaching.

Teknik pengumpulan data yang digunakan dalam penelitian ini ada tiga cara yaitu, 
Peningkatan Kompetensi Mahasiswa UIN Sunan Gunung Djati Bandung dalam Merancang RPP Matematika

observasi, wawancara, angket dan penilaian produk RPP mahasiswa.; 1) Observasi; 2) Wawancara; 3) Angket; 4) Dokumentasi dan 4) Teknik test pembuatan RPP berbasis Nilai Islam.

Peneliti membagi pada dua jenis data penelitian, yakni sumber data primer dan sumber data sekunder. Sumber data primer, yaitu data-data yang terdapat di tempat penelitian dan dari buku-buku referensi yang berkitan langsung dengan pembahasan.

Pengumpulan data didasarkan pada petunjukpetunjuk pada penelitian kualitatif, khususnya untuk format studi kasus. Teknik tersebut secara berurutan terdiri atas empat tahap, yaitu orientasi, eksplorasi, pengecekan sejawat (member check) dan triangulasi.

\section{HASIL DAN PEMBAHASAN}

Model pembelajaran matematika yang mengintegrasikan nilai-nilai Islam bagi mahasiswa Prodi pendidikan matematika, berdasarkan hasil observasi wawancana dan penyebaran angket kepada dosen dan mahasiswa diperoleh informasi berkaitan dengan model perkuliahan di Prodi matematika dalam menanamkan nilai-nilai Islam sebagai visi dari UIN Sunan Gunung Djati Bandung yakni " wahyu memandu Ilmu”.dikembangkan melalui 1) Perencanan Perkuliahan yang memasukan nilai-nilai Islam, dalam merumuskan SAP (Satuan acara Perkuliahan) 2) model Pengintegrasian Nilainilai Islam dalam bahan perkuliahan bidang matematika ; 3) menyampaikan nilai Islam secara a) lisan yakni selama perkuliahan baik secara langsung maupun tidak langsung, atau secara tertulis dengan memunculkan dalam SAP dalam bahan Ajar dan dalam evaluasi. Implementasi pengembangan model penanaman nilai Islam dalam perkuliahan dari perencanaan dan pelaksanaan pengajaran yang dilakukan dosen termasuk kategori rendah.

Kemampuan mahasiswa dalam menyusun RPP Matematika dan RPP matematika berbasis nilai Islam dilakukan penilaian terhadap hasil produk RPP mahasiswa oleh 3 orang ahli yaitu ahli matematika, ahli bahasa dan ahli Agama Islam, untuk RPP matematika di nilai aspek 1) Kejelasan identitas mata pelajaran; 3) Kejelasan rumusan indikator dan tujuan pembelajaran; 3) Kejelasan topik dan materi pembelajaran; 4) kesesuaian metode/ strategi/ pendekatan/ langkah-langkah pembelajaran dengan topik dan peserta didik; 5) Kesesuaian pemilihan alat, media, dan sumber belajar belajar dengan topik, strategi pembelajaran, dan peserta didik; 6) Kesesuaian penilaian dengan indikator dan tujuan pembelajaran,; 7) Kelengkapan perangkat pembelajaran (RPP, alat, media, sumber belajar, bahan ajar, alat penilaian),

Data menunjukan bahwa kemampuan menyusun RPP matematika dapat dilihat pada

diagram berikut :

Kemampuan Mahaiswa menyusun RPP Matematika

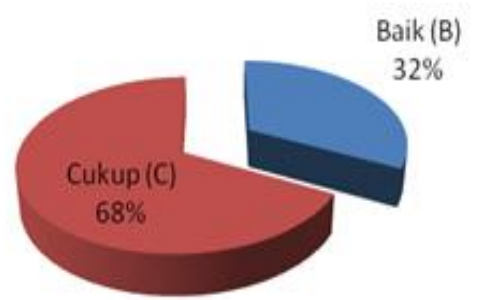

Diagram 1 Kemampuan Mahasiswa Menyusun RPP Matematika

Diagram 1 menunjukan mahasiswa yang memperoleh nilai Baik sebanyak 32\% dan yang memperoleh nilai cukup 68\%, hal ini menunjukan kemampuan mahasiswa masih belum optimal, Skor rata-rata kemampuan mahasiswa dalam menyusun RPP matematika adalah 78,29 termasuk kategori cukup.

Sementara itu kompetensi mahasiswa dalam menyusun RPP berbasis keislaman dalam aspek: 1) Nilai Islam dimunculkan dalam tujuan di RPP; 2) Nilai Islam dimasukan 
dalam materi pelajaran; 3) Nilai Islam dikembangkan dalamproses pelaksanaan pelajaran; 4) Niai Islam dimunculkan dalam evaluasi pembelajaran dan 5) Tidak memunculkan nilai-nilai Islam sama sekali. Kompetensi mahasiswa dalam menyusun RPP berbasis Nilai Islam, terlihat pada gambar berikut:

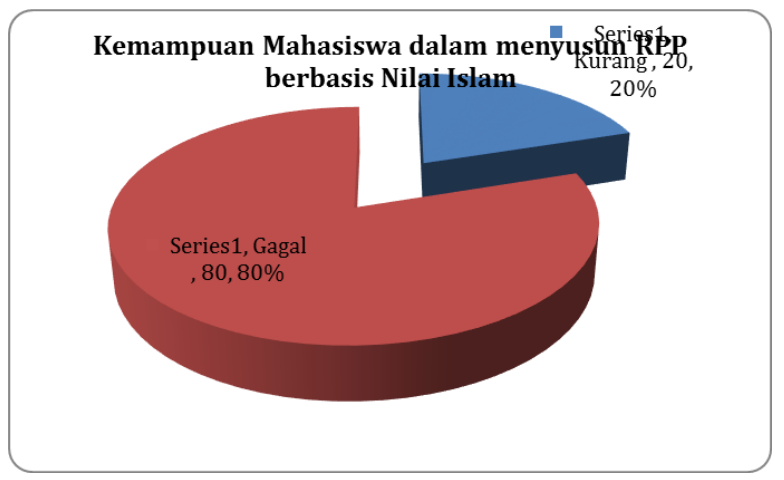

Diagram 2 Kemampuan Mahasiswa Menyusun RPP Berbasis Nilai

Diagram 2 menunjukan mahasiwa sama sekali tidak mampu menyusun RPP matematika berbasis keislaman, 80\% termasuk kategori gagal, sekor rata-rata kemampuan mahasiswa adalah 55.7 termasuk kategori gagal atau tidak mampu.

\section{KESIMPULAN}

Model pembelajaran matematika yang mengintegrasikan nilai-nilai Islam bagi mahasiswa Prodi pendidikan matematika, dalam menanamkan nilai-nilai Islam sebagai visi dari UIN Sunan Gunung Djati Bandung yakni " wahyu memandu Ilmu”.dikembangkan melalui 1) Perencanan Perkuliahan yang memasukan nilai-nilai Islam, dalam merumuskan SAP (Satuan acara Perkuliahan) 2) model Pengintegrasian Nilai-nilai Islam dalam bahan perkuliahan bidang matematika ; 3) menyampaikan nilai Islam secara a) lisan yakni selama perkuliahan baik secara langsung maupun tidak langsung, atau secara tertulis dengan memunculkan dalam SAP dalam bahan Ajar dan dalam evaluasi. Implementasi pengembangan model penanaman nilai Islam dalam perkuliahan dari perencanaan dan pelaksanaan pengajaran yang dilakukan dosen termasuk kategori rendah.

Kompetensi mahasiswa dalam menyusun RPP berbasis nilai Islam adalah : a) Kompetensi mahasiswa mahasiswa dalam merumuskan RPP matematika diukur dengan menilai produk RPP menunjukan bahwa kemampuan menyusun RPP mahasiswa yang memperoleh nilai Baik sebanyak 32\% dan yang memperoleh nilai cukup 68\%, hal ini menunjukan kemampuan mahasiswa masih belum optimal, Skor rata-rata kemampuan mahasiswa dalam menyusun RPP matematika adalah 78,29 termasuk kategori cukup; b) Kompetensi mahasiswa dalam menyusun RPP berbasis keislaman dalam aspek Nilai Islam sebesar 80\% termasuk kategori gagal, sekor rata-rata kemampuan mahasiswa adalah 55.7 termasuk kategori gagal atau tidak mampu.

Dari kesimpulan tersebut maka ada beberapa implikasi yang bisa diajukan: a) Perlu dikembangakan singkronisasi antara model dengan implementasi di lapangan, sehingga program, Prodi Matematika dalam merumuskan RPP berbasis nilai Islam harus di tunjang denbgan keinginan dan kemampuan dosen untuk melakukanya, hal ini bisa dilakukan dengan membuat rumusan bersama antara program studi Matematika dengan seleluruh elemen dosen sehingga ada rumusan esensi yang dibuat bersama; b) Membutuhkan penguatan mahasiswa dalam merumuskan RPP berbasis keislaman dengan mengintegrasikan pembelajaran matematika dengan nilai-nilai Islam secara terus menerus

\section{DAFTAR PUSTAKA}

Abdusyakir. (2007), Bila Kyai Mengajara Matematika, Malang, UIN Malang Press

Abdussakir. (2005). Matematika dan alQur'an. Disajikan pada Seminar Integrasi Matematika, al-Qurean, dan Kehidupan Sosial, 3 Agustus 2005, Topografi 
Peningkatan Kompetensi Mahasiswa UIN Sunan Gunung Djati Bandung dalam Merancang RPP Matematika

Berbasis Nilai-Nilai Islam

Komando Daerah Militer V Brawijaya, Malang.

. (2006a). Ada Matematika dalam Al-Qur'an. Malang: UIN-Maliki Press.

- (2006b). Pola matematika pada surat al-'Ashr, al-Kautsar, dan an-Nashr. Laporan Penelitian tida dipublikasikan. Lembaga Penelitian dan Pengabdian kepada Masyarakat Universitas Islam Negeri Maulana Malik Ibrahim Malang, Malang.

- (2007). Ketika Kyai Mengajar Matematika. Malang: UIN-Maliki Press.

.(2009). Matematika 1: Kajian Integratif Matematika dan Al-Qur'an. Malang: UIN-Maliki Press.

Abdullah, Amin, (2014). Praksis Paradigma Integrasi Interkoneksi Ilmu dan Transformasi Islamic Studies. Makalah diseminarkan di Program Pascasarjana UIN Sunan Kalijaga Yogyakarta, 22-23 Oktober 2014, hal 3

Al-Kahil, (2008). Misteri Angka: Dalam Mukjizat Matematika Al-Qur'an. Jakarta: Sahara.

An-Najdi, (2006). Al-Qur'an dan Rahasia Angka-angka. Diterjemahkan oleh Agus Effendi. Bandung: Pustaka Hidayah.

Basya, F. (2003). Matematika Al-Qur'an. Jakarta: Pustaka Quantum Prima. .(2005). Matematika Islam. Jakarta: Penerbit Republika.

Black, S. (2003). The Creative Classroom. American School Board Jurnal September 2003, $p$ 68-70.
Bishop. (2001). What Values Do You Teach When You Teach Mathematics? Teaching Children Mathematics (Ed. Anne Reynolds dan Jim Dorward). Australian Research Council and Jointly Conducted by Monash University.

Brog dan Gall,(1979), Educational Research An Introduction, New York, Souten Press.,

Ernest,P. (1991). The Philosophy of Mathematics Education. London: RoutledgeFalmer.

Gagne, R.M. (1975). Essentials of learning for Instruction: Expanded Edition. New York: Holt, Rinehart and Winston.

Joyce, Bruce. dan Marsha Weil. (1992). Models of Teaching. Allyn ang Bacon, Massachussets.

Karso, dkk., (2014), Materi Pokok Pendidikan Matematika I, Universitas Terbuka.

Khalifa,(1974). One of the Great Miracle. (Online) http://www.submission.org/Appendix_1/ one_of_the_great_miracle.htm (diakses 12 Pebruari 2006).

Komariah, Aan.dkk (2011). Manajemen Pendidikan. Bandung: Alfabeta.

Muniri. (2016). Kontribusi Matematika dalam Konteks Fikih. Ta'allum, 04(02): 193-214.

Moleong, Lexi J. (2002). Metode Penelitian Kualitatif. Bandung: Remaja Rosada

Nanat 2011 wahyu memandu Ilmu, UIN SGD Bandung

Rosimanidar. (2012). Internalisasi Nilai-nilai Qur'ani dalam Pembelajaran Matematika. Laporan Hasil Penelitian 
tidak dipublikasikan. Lhokseumawe: STAIN Malikussaleh Lhokseumawe.

(2013a). Pengembangan Pembelajaran Aljabar SMP Berbasis Nilai-Nilai Akhlak. Laporan Hasil Penelitian tidak dipublikasikan. Lhokseumawe: STAIN Malikussaleh Lhokseumawe.

(2013b). Peran Guru Menginternalisasikan Nilai-Nilai Qur'ani Dalam Pembelajaran Matematika Sebagai Wujud Revitalisasi Perguruan Tinggi Islam Di Era Globalisasi. Makalah disampaikan dalam Seminar Nasional Matematika dan Pendidikan Matematika oleh Jurusan Matematika UIN Maulana Malik Ibrahim Malang, tanggal 18 Mei 2013.

Sugilar, H. 2017. Implementasi Model Perkuliahan Assessment for Learning dalam Meningkatkan Kemampuan Pembuktian pada Mahasiswa Pendidikan Matematika. Jurnal Perspektif, 1(1): 11-19. Dapat diakses di: perspektif.uinsgd.ac.id/index.php/JP/artic le/download/2/2

Tafsir, Ahmad. (2006)Filsafat Pendidikan Islami; Integrasi Jasmani, Rohani dan Kalbu Memanusiakan Manusia, cetakan pertama. Jakarta: Remaja Rosdakarya. 